\title{
Московский журнал «Украинская жизнь» (1912-1917 гг.) в современной российской и украинской историографии
}

\author{
P.В. Трофимов, А.Н. Мошкин \\ Белгородский государственный национальный исследовательский университет, \\ Россия, 308015, г. Белгород, ул. Победы, 85; \\ E-mail: troro@mail.ru
}

\begin{abstract}
Аннотация. В статье рассматривается современная российская и украинская историография, журнала «Украинская жизнь» (1912-1917 гг.). Отмечается недостаток изучения в России проукраинской периодики в целом и данного журнала в частности. Выявлены взгляды современных украинских исследователей, которые провели достаточно тщательное исследование журнала, в основном с филологической, журналистской, культурологической и исторической точек зрения. Делается вывод о том, что издаваемый в Москве журнал пропагандировал идеи украинского национализма, который активно противостоял национальной политике русского правительства в рамках концепции триединого русского народа.
\end{abstract}

Ключевые слова: украинский язык, «украинский вопрос» в Российской империи, малороссы, сепаратизм, автономизм.

Для цитирования: Трофимов Р.В., Мошкин А.Н. 2020. Московский журнал «Украинская жизнь» (1912-1917 гг.) в современной российской и украинской историографии. Via in tempore. История. Политология. 47(4): 854-862. DOI: 10.18413/2687-0967-2020-47-4-854-862.

\section{Moscow magazine «The Ukrainian life» (1912-1917) in modern Russian and Ukrainian historiography}

\author{
Roman V. Trofimov, Alexander N. Moshkin \\ Belgorod National Research University, \\ 85 Pobedy St., Belgorod, 308015, Russia; \\ E-mail: troro@mail.ru
}

\begin{abstract}
The article reveals the historiography, content and main ideas of magazine «The Ukrainian Life» (1912-1917). The author analyzes research of the magazine in Russian and Ukrainian science, identifies directions for its further study. The author of the article also notes that in national science the pro-Ukrainian periodicals in general and the analyzed magazine in particular have yet to be adequately examined. The article considers the views of modern Ukrainian researchers who conducted a fairly thorough research of the magazine, mainly from the philological, journalistic, cultural and historical points of view. The issue of the scale of the magazine's significance for the ongoing nation-building in the Russian Empire is also important. Ukrainian historiography is inclined to exaggerate the role of this magazine in the «national revival of Ukrainians in Moscow», but the fact is indisputable that the magazine «The Ukrainian Life» was an active spokesman for the few (at that time) activistsUkrainophiles of the Russian Empire. We see directions for further research in a comprehensive study of the magazine, its impact on Russian society and discussions on the pages of publications. It is concluded that the magazine published in Moscow promoted the ideas of Ukrainian nationalism, that within the framework of the concept of the triune Russian people actively opposed the national policy of the Russian government.
\end{abstract}

Keywords: Ukrainian language, «Ukrainian issue» in Russia, Little Russian, separatism, autonomism. 
For citation: Trofimov R.V., Moshkin A.N. 2020. Moscow magazine «The Ukrainian life» (1912-1917) in modern Russian and Ukrainian historiography. Via in tempore. History and political science. 47(4): 854-862 (in Russian). DOI: 10.18413/2687-0967-2020-47-4-854-862.

\section{Введение}

Одной из актуальных тем последних десятилетий является изучение национальных движений окраин Российской империи. Безусловно, в этом процессе одним из самых активных движений были объедения украинофилов, добивавшихся культурной автономии в составе России. Наиболее активно деятели украинской идеи проявляли себя в «украинских» губерниях. По переписи 1897 г. удельный вес малороссов в девяти «украинских» губерниях составлял около $80 \%$, опускаясь в Таврии до $42 \%$. А в ведущих городских центрах, традиционно господствующих над сельской округой, малороссы представляли собой незначительное меньшинство - в среднем не более пятой части всех их обитателей [Первая всеобщая перепись населения Российской империи, 2020]. Что касается крупных великорусских городов, то здесь малорусского населения было не более одного процента. Например, в Москве малороссов начитывалось всего четыре с половиной тысячи человек или $0,43 \%$. После окончания Первой русской революции в 1907 году, ослабления цензуры и общей либерализации общества в Малороссии стали выходить газеты и журналы проукраинской направленности (например, «Хлебороб», «Рада» и т. д.) на украинском языке. Нашлись сторонники «украинской идеи» и в столице Российской империи - в СанктПетербурге, где с 1906 года начал свой выход русскоязычный еженедельник «Украинский вестник» [Корнієвська, 2013, с. 220]. Однако, недолго просуществовав, в этом же году он был закрыт.

Спустя 6 лет после революционных событий с украинофильской тематикой в Москве на русском языке стал выходить журнал «Украинская жизнь». Главные редакторы журнала А. Саликовский и С. Петлюра, описывая журнал как, прежде всего, культурнопросветительский, скрывали его политическую направленность, и поэтому разрешение на издательство в Московском комитете по делам печати было получено. Немногочисленная украинская диаспора, проводя свою агитацию в «чужих» губерниях, ставила целью объединение земляков-малороссов, превращение их в украинцев и «просвещение» великорусской интеллигенции, которая не считала важным «украинский вопрос». Действительно, недооценка опасности украинского сепаратизма со стороны российской власти дорого обошлась новой, уже республиканской России после 1917 года, когда украинский сепаратизм получил поддержку со стороны различных сил, что в конченом итоге привело к расколу русского народа и созданию государства Украина.

В целом этот русскоязычный журнал представлял собой сборник статей деятелей украинского движения и делился на несколько непостоянных рубрик: 1) «На текущие темы»; 2) «Обзор украинской жизни»; 3) «На Украине и вне ее»; 4) «Библиография», 5) «Объявления»; 6) «Украинская пресса», 7) «Из русской печати», 8) «Ответы читателям» и т. д. Тираж в основном составлял до 500-1000 штук, объем выпуска - до 200 журнальных страниц. Исходя из анализа содержания издания, статей, дискуссий на страницах журнала «Украинская жизнь», можно сделать вывод, что в завуалированной форме в Москве пропагандировалась идея украинского национализма с собственной исторической мифологией, ядро которой составило желание создать автономную Украину с правом на культурное самоопределение [«Украинская жизнь», журнал (Москва), 1917]. Важное внимание в журнале уделялось «угнетению» украинского народа Россией («Москвой»), которая лишила, по мнению украинофилов, украинцев государственности. В дальнейшем подобные идеи станут основой уже современной украинской исторической политики. 


\section{Объекты и методы исследования}

Объектами исследования являются основные идеи, деятельность и роль в современном историческом нарративе России и Украины журнала «Украинская жизнь» (1912-1917 гг.). Проанализированы современные российские и украинские труды ученых, касающихся издания, его редакторов. Из основных собственно исторических методов научного исследования использовались:

- историко-типологический - для выявления основных идей и подходов исследователей журнала;

- историко-системный - для изучения явления особенностей российской и украинской историографий в контексте изучения журнала;

- проблемно-хронологический - для раскрытия истории изучения журнала в России и за рубежом;

- мы подходили в истории изучения журнала к весьма сложному феномену в области политики, литературы, теории журналистики, поэтому необходим также междисциплинарный подход;

- кроме того, целесообразен структурно-функциональный подход для изучения историографии журнала в контексте всей историографии как России, так и Украины.

\section{Результаты и их обсуждение}

В историографии первая серьезная попытка изучения журнала в России была предпринята в 1994 году Н.М. Пашаевой [Пашаева, 1994], которая в своей статье рассмотрела основные направления деятельности и тематику издания. Через 21 год появилась вторая статья М.Э. Клоповой, которая посвящена «Украинской жизни» [Клопова, 2015]. Исследователь рассматривает основные противоречия, которые возникали между русской интеллигенцией и активистами украинского движения. По мнению М.Э. Клоповой, ежемесячник представляет интерес «...не только как собственно украинский журнал, но и как явление российской общественной мысли» [Там же, с. 123]. Вместе с тем «Украинская жизнь» не смогла занять место «рупора украинского движения», отстранившись от актуальных тем российской действительности, что стало причиной непонимания между украинскими активистами и русской оппозиционной общественностью. Как отмечет автор статьи, другой преградой было то, что проукраинские деятели стремились придать «украинскому вопросу» статус исключительности, в то время как для русских читателей этот вопрос был лишь частью общей борьбы за «...преобразования всего российского общества в демократическом духе» [Там же, с. 135]. К сожалению, в отечественной науке публикации М.Э. Клоповой и Н.М. Пашаевой [Пашаева, 1994] остаются едва ли не единственными исследованиями, посвященными этому украинофильскому изданию, которое, по нашему мнению, представляет собой явление незаурядное - на протяжении пяти лет в древней российской столице регулярно выходил журнал, пропагандировавший идеи украинства (украинцев как отдельного народа), которые противоречили официальной национальной политике Российской империи.

В современной Украине на журнал активно обращали внимание в двухтысячные годы. Так, филологом О.О. Полумысной раскрыты композиционные особенности статей на литературную тему [Полумисна, 2007б], журнал был рассмотрен с позиций литературного процесса - изучена та сторона журнала, которая касалась украинских писателей того времени: И. Франко, Л. Украинка, О. Кобылянская и т. д. [Полумисна, 2007а]. В статье «Организационная деятельность редакторского состава журнала "Украинская жизнь“» (1912-1917 гг.) исследуется организационная деятельность редакторского состава: Я. Шеремецинский, С. Петлюра и А. Саликовский [Полумисна, 2009а, с. 192].

В диссертации О.О. Полумысной «Журнал "Украинская жизнь“ и литературный процесс начала XX века» отмечено, что «...журнал «Украинская жизнь» (1912-1917 гг.) по- 
ка оставался вне научных поисков» (здесь и далее перевод с украинского языка автора Р.Т.) [Полумисна, 2009б, с. 7]. Обращает внимание замечание автора, что в советское время журнал игнорировался, и упоминания о нем встречаются без какой-либо аналитики. В диссертационной работе О.О. Полумысной сосредоточено внимание на культурнолитературных аспектах «Украинской жизни», с точки зрения теории литературы и журналистики изучена тематика журнала. По мнению автора: «”Украинская жизнь“ не преследовала откровенно политических целей, своей открытостью и неангажированностью она привлекла к себе многих читателей» [Там же, с. 9]. Возразим, что в подобных оценках чувствуется политическая предопределенность взглядов О.О. Полумысной, ведь по ее мнению «украинская нация» уже тогда представляла собой нечто завершенное и отдельное от русского народа, поэтому журнал ей представляется «не откровенно политическим» и «неангажированным». Неудивительно, что в статье «Деятельность журнала "Украинская жизнь“ (1912-1917) в оценке украинских и российских периодических изданий начала XX века» [Полумисна, 2010] исследователь практически обходит стороной критические отзывы на деятельность журнала, фокусируясь в основном на позитивных отзывах публицистов. Вместе с тем, как показывает изучение периодической печати того времени, среди русской (как малорусской, так и великорусской) прессы существовало огромное количество негативных отзывов [Клопова, 2015] как о тематике и содержании журнала, так и об украинстве в целом. Итак, нельзя сказать, что журнал был «неангажированным», ведь целью журнала было, прежде всего, изменить национальную государственную политику России, направленную на построение триединой русской нации, показать отличия малороссов и великороссов, очернить русское националистическое движение, важную часть которого составляли малороссы Киева, Харькова, Полтавы, Житомира и других городов.

В другой работе О.О. Полумысная приводит цитату Д. Донцова - одного из ключевых авторов журнала: «Редакция ”Укр. Жизни“ смотрела на нее как на орган проукраинской пропаганды среди русских, я - как на орган противорусской пропаганды среди украинцев» [Цит. по: Полумисна, 2014, с. 292]. Таким образом, материал журнала скорее носил определенную пропагандистскую цель. В целом в трудах многих украинских исследователей прослеживается подобная предопределенность в правильности идей журнала, уверенность в существовании «украинской нации» со своими интересами, отличными от общероссийских, игнорируя активную деятельность многих малороссов, которые считали себя частью единой русской нации.

В другой украинской диссертации Д.И. Миронюка «Симон Петлюра как редактор журнала "Украинская жизнь“ (1912-1917 гг.)» с точки зрения специалиста по социальным коммуникациям освещены программные основы журнала, организация работы редакции, тематика и направления работы журнала. Отметим, что это исследование основное внимание уделяет личности редактора «Украинской жизни» - С. Петлюре «...как журналисту, публицисту, редактору, организатору редакционно-издательского дела» [Миронюк, 2011, c. 5]. Также укажем на то, что в диссертации были использованы архивные документы (из ЦГАВОВУ и ЦГИАУ в Киеве), касающиеся проукраинской периодики, особенностей взаимодействия с местной властью и становления Симона Петлюры как журналиста. Тем не менее, по нашему мнению, в работах Д.И. Миронюка наблюдается ряд упущений, связанных с исторической объективностью, эмоциональностью изложения, касающихся «украинского вопроса» в России. Так, например, в статье «Журнал ”Украинская жизнь“ - как фактор защиты украинского языка в условиях наступления реакционных сил на национально-освободительное движение» Д.И. Миронюк утверждал, что «...в царской России названия "Украина“, "украинцы“, ”украинский“ были административно запрещены. Распоряжение это было тайным, потому что, с одной стороны, оно было противозаконным, а с другой - граждане лишались возможности обжалований» [Миронюк, 2009, с. 425]. Спорными являются утверждения о «тайных распоряжениях», о запрете всего украинского, ведь само название журнала содержало слово «украинская», и на его страницах в 
Москве не только употреблялись термины «Украина», «украинцы» и т. д., но еще и обосновывалось право на собственную культуру и язык. Кроме того, в диссертационном исследовании допущен ряд ангажированных высказываний вроде «...столице тогдашней "тюрьмы народов“" - Москве» [Миронюк, 2011, с. 11] или «...петлюровские идеи не утратили методологического значения [...] в контексте современной внутренней, внешней информационной политики, единение нации вокруг идеи независимости и строительства прочного суверенного государства» и т. д. [Миронюк, 2011, с. 4]. Но вместе с тем ценным в работах Д.И. Миронюка является использование большого массива источниковедческого и историографического материала.

Отдельные аспекты деятельности журнала освещены в работах другого украинского исследователя - Ю.О. Безкровного. Были проанализированы данные анкетирования, которое провела редакция «Украинской жизни» среди русских деятелей по «украинскому вопросу» [Безкровний, 2015б]. Опрос проводился в основном среди либеральной и социал-демократической общественности, поддерживающей или нейтрально относящейся к «самоопределению украинского народа». Ответы на вопросы даны и теми, кто публиковался в «Украинской жизни», например, Ф. Коршем [Корш, 1912] и А. Луначарским [Луначарский, 1912]. Следует отметить, что это анкетирование сложно назвать релевантным ведь большинство респондентов были представлены проукраинским лагерем. Были даны ответы в логике украинского движения того времени: украинцы являются и хотят быть частью Российского государства, но они - отдельный народ, которому необходима автономия в рамках единой страны. Как отмечает Д.И. Миронюк, редакция журнала опубликовала и два негативных отзыва об украинском движении, один из них - князя Е. Трубецкого, который отображал распространенное мнение об «украинской проблеме» в то время: «...[не существует] ни украинской, ни великорусской народности: мы здесь имеем два разветвления одного русского народа и два очень близких наречия одного русского языка» [Цит. по: Безкровний, 2015б, с. 158]. По мнению редакторов «Украинской жизни», такого рода отзывы «...отражают мысли, более-менее распространенные в тех кругах русского общества» [Там же, с. 158]. В целом, как мы отмечали выше, это было отображение, как официальной точки зрения Российской империи, так и многих политиков разных взглядов, от умеренно-либеральных до консервативных. Русские националисты рассматривали идеи, выдвинутые в «Украинской жизни», «...как сепаратизм, на который должна последовать реакция властей» [Колмаков, 2010, с. 48].

В другой статье Ю.О. Безкровного была исследована редакторская деятельность С. Петлюры [Безкровний, 2016]. Интересно, что в первые годы существования журнала С. Петлюра сомневался в необходимости продолжать издавать журнал из-за равнодушия русской публики к «украинскому вопросу». Ю.О. Безкровный в своем исследовании также пишет о разногласиях среди ведущих публицистов журнала. Так, у С. Петлюры были серьезные разногласия с другим редактором - А.Ф. Саликовским, который не поддерживал «...недоверие ко всему русскому и стремление отделиться в тесно ограниченный круг своих национальных интересов» [Цит. по: Безкровний, 2016, с. 31]. Во многом из-за таких идеологических противоречий Саликовский вышел из редакторского состава издания. Как отмечает Ю.О. Безкровный, «это было единственное украинское издание, которому удалось удержаться во время цензурной вакханалии 1914-1915 годов, прежде всего благодаря мудрому руководству редактора» [Там же, с. 32]. Действительно, в статье «Война и украинцы» в 1914 году С. Петлюра поддержал Российскую империю как родину украинцев и других народов, что, безусловно, повлияло на решение не закрывать этот журнал.

В работе Ю. Безкровного «Журнал "Украинская жизнь“ и цензура» [Безкровний, 2015в] изучены случаи обращения Московского комитета по делам печати к журналу «Украинская жизнь» в течение 1913-1915 годов, во время которых было открыто несколько судебных дел, сопровождавшиеся допросами, конфискациями, штрафами. Ведомством проводился регулярный мониторинг содержания журнала. По мнению автора статьи, такое внимание бы- 
ло спровоцировано противниками украинского движения, «...но искусственность и надуманность обвинений способствовали позитивному для редакции решению этих дел» [Безкровний, 2015в, с. 90]. Ю. Безкровный считает, что редакция журнала, прибегая к самоцензуре и повышенным требованиям к каждому номеру журнала, смогла удержать издание от закрытия. Помимо «Украинской жизни», сторонники украинского движения успешно издавали в Москве в военное время на малороссийском наречии журнал «Промінь», который редактировал В. Винниченко при поддержке М, Грушевского, считавший, что «...”Украинская жизнь“ не удовлетворяла многих московских украинцев, она была журналом "для наружного употребления“» [Цит. по: Безкровний, 2015a, с. 163]. Таким образом, некоторые деятели украинства были недовольны «умеренностью» «Украинской жизни».

Современный украинский исследователь Г. Сергийчук подчеркивал особую роль историка М. Грушевского в развитии и становлении журнала [Сергійчук, 2016]. На основе архивных документов раскрываются предпосылки основания в Москве издания «Украинская жизнь», роль Грушевского в этом процессе, дальнейшее его сотрудничество с изданием. Особое внимание уделяется пребыванию автора многотомного учебника по украинской истории «в ссылке»- в Москве с сентября 1916 до марта 1917 года, когда он непосредственно участвовал во всех важнейших мероприятиях украинофилов Москвы, в частности в создании журнала «Промінь». Грушевский признавал, что «Украинской жизни» в Москве «...вдруг суждено тогда стать единственным украинским органом», и «...теперь приходилось пользоваться им как единственной трибуной» [Цит. по: Сергійчук, 2016, с. 74].

Различные аспекты деятельности «Украинской жизни» осветил другой украинский исследователь - В.С. Идзьо. Работа «”Украинская жизнь“ - научно-литературный и общественно-политический журнал украинцев Москвы и России в 1912-1917 годах» [Ідзьо, 2015a] представляет собой сборник статей автора, в которых изучена позиция журнала касательно «украинского вопроса», проблемы «мирового украинства», «украинской диаспоры» в России. Рассмотрены личности деятелей украинского движения на страницах журнала: Михаил Грушевский, Семен Петлюра, Леся Украинка, Тарас Шевченко, Иван Франко, Митрополит Андрей Шептицкий. Как и вышеупомянутые украинские исследователи, В.С Идзьо очень высоко оценивает материал и ценность журнала. По мнению автора «... журнал "Украинская жизнь“ наполнен конкретным профессиональным содержанием, который, охватывая комплекс украинских проблем и запросов украинской общественности не только Москвы и России и Украины, не ограничивал себя рамками политической жизни, а пытался охватывать проблемы культуры, истории, науки [...] в "Украинской жизни“ М.С. Грушевский открыто поднял перед российским государством, российским обществом концепцию проблемы исторического восстановления украинской государственности, что требует дальнейшего исследования» [Ідзьо, 2015б, с. 21]. Нельзя не согласиться с тем, что журнал требует комплексного исследования, ведь с учетом специфики национального строительства в Российской империи и либерализации общества происходит и изменение подхода власти к проблеме украинства, что приводит в итоге к краху концепции триединой русской нации, которая была официальной долгое время. Кроме того, возникает вопрос: каким образом в военное время выходило издание, в котором могли быть такие сепаратистские призывы, если даже и тщательно замаскированные под патриотизм.

\section{Заключение}

Таким образом, современные украинские исследователи провели достаточно тщательное исследование журнала, в основном с филологической, журналистской, культурологической [Козар, 2014] и исторической точек зрения. На Украине журналу посвящены две диссертации и более дюжины научных публикаций. Однако мы можем выделить несколько недостатков в изложении материала: во-первых, для этих авторов украинское движение является бесспорными борцом «за правду», против «имперского угнетения», «великорусского шовинизма» и т. Д. Для вышеупомянутых украинских исследователей 
существование украинской нации в начале XX века является фактом, они полностью согласны с позицией редакции журнала, выступают его защитниками, слабо присутствует критика позиции украинофилов. Во-вторых, почти игнорируется прорусская сторона (в лице умеренных либералов и консерваторов в Малороссии и остальной России), которая критически отвечала на публикации, и если она и упоминается, то представлена как глупость и оскорбление здравого смысла. Важен также вопрос о масштабе значимости журнала для тогдашних национальных процессов в России. Украинская историография склонна преувеличивать роль этого издания в «национальном возрождении украинцев Москвы», но бесспорным является тот факт, что журнал «Украинская жизнь» являлся активным выразителем немногочисленных тогда деятелей украинского движения в Российской империи. Перспективы дальнейших исследований мы видим в комплексном изучении журнала, его влияния на русское общество и дискуссий на страницах изданий.

\section{Список источников}

1. Корш Ф.Е. 1912. К спору об украинской культуре. Украинская жизнь, 2: 32-43.

2. Луначарский А.Н. 1912. О национализме вообще и украинском движении в частности. Украинская жизнь, 10: 10-19.

3. Первая всеобщая перепись населения Российской империи 1897 г. Электронный ресурс. URL: http://www.demoscope.ru/weekly/ssp/census.php?cy=0 (дата обращения: 17 ноября 2020).

4. «Украинская жизнь», журнал (Москва). 1917. Указатель статей и заметок, напечатанных к «Украинской жизни» в 1912-1916 гг. М., 44 с.

\section{Список литературы}

1. Безкровний Ю.О. 2015а. Володимир Винниченко як редактор журналу «Промінь» (1916-1917). Наукові праці історичного факультету Запорізького національного університету, 43 : $162-167$.

2. Безкровний Ю.О. 2015б. Анкета журналу «Украинская жизнь» 3 національного питання. Вісник Харківського національного університету імені В.Н. Каразіна. Серія: Історія, 50: 154-160.

3. Безкровний Ю.О. 2015в. Журнал «Украинская жизнь» і цензура (1912-1917). Етнічна історія народів Свропи, 46: 86-92.

4. Безкровний Ю.О. 2016. Журналістська діяльність Симона Петлюри в Петербурзі та Москві. Наукові записки НаУКМА. Історичні науки, 182: 27-35.

5. Ідзьо В.С. 2015а. «Украинская жизнь» - науково-літературний і громадсько-політичний журнал українців Москви та Росії у 1912-1917 роках. Львів, Українознавець: 170.

6. Ідзьо В.С. 2015б. Михайло Грушевський на шпальтах часописів українців Росії «Украинский Вестник» та «Украинская Жизнь» першій чверті ХХ століття. Івано-Франківськ, «Сімик»: 24.

7. Клопова М.Э. 2015. «Больной вопрос». Анкета журнала «Украинская жизнь» 1912-1917 гг. Славянский альманах, 3-4: 122-137.

8. Козар Л. 2014. Висвітлення фольклористично-етнографічної діяльності Павла Чубинського на сторінках журналу «Украинская жизнь». Слов'янський світ, 13: 260-272.

9. Колмаков В.Б. 2010. Об одном националистическом нарративе начала ХХ века. Вестник Воронежского государственного университета. Серия: Философия, 1 (3): 48-61.

10. Корнієвська О. В. 2013. «Украинский вестник» - тижневик (1906). Енциклопедія історії України : у 10 т. Київ: Наукова думка, Т. 10: 220.

11. Миронюк Д.І. 2011. Симон Петлюра як редактор журналу «Украинская жизнь» (1912-1917 рр.). Автореф. дис. ... канд. наук із соц. комунікацій. Київ: 20.

12. Миронюк Д.І. 2009. Журнал «Украинская жизнь» - як чинник захисту української мови в умовах наступу реакційних сил на національно-визвольний рух (1912-1917рр.). Наукові праці Кам'янець-Подільського національного університету імені Івана Огієнка. Філологічні науки, 20: $420-425$.

13. Михутина И.В. 2003. Украинский вопрос в России (конец XIX - начало XX века), М., «Ловатера»: $287 \mathrm{c}$. 
14. Пашаева Н.М. 1994. Журнал «Украинская жизнь». Библиотека и история, 3: 81-101.

15. Полумисна О.О. 2007а. Народництво і модернізм в інтерпретації літературних критиків журналу «Украинская жизнь» (1912-1917) // Вісник Харківського національного університету ім. В.Н. Каразіна, 766. Сер. Філологія. 51: 71-75.

16. Полумисна О.О. 2007б. Композиційні особливості літературно-критичних матеріалів журналу «Украинская жизнь» (1912-1917рр.). Вісник Харківського національного університету ім. В.Н. Каразіна, 787. Сер.: Філологія, 52: 297-301.

17. Полумисна О.О. 2009а. Організаційна діяльність редакторського складу журналу «Украинская жизнь» (1912-1917 рр.). Вісник Харківського національного університету ім. В.Н. Каразіна, 846. Сер.: Філологія, 56: 191-196.

18. Полумисна О.О. 2009б. Журнал «Украинская жизнь» і літературний процес початку XX століття. Автореф. дис. ... канд. філол. наук. Харків: 19.

19. Полумисна О.О. 2010. Діяльність журналу «Украинская жизнь» (1912-1917) в оцінці українських i російських періодичних видань початку XX століття. Вісник Харківського національного університету ім. В.Н. Каразіна. № 910. Сер.: Філологія, 60, част. II: 412-415.

20. Полумисна О.О. 2014. Симон Петлюра: літературний критик, публіцист, редактор. Вісник Львівського університету. Серія: Журналістика, 39(1): 289-296.

21. Сергійчук Г. 2016. Співпраця М. Грушевського з українцями Москви на початку ХХ століття. Схід, 4 (144): 73-78.

\section{References}

1. Bezkrovnij Ju.O. 2015a. Volodimir Vinnichenko jak redaktor zhurnalu «Promin» (1916-1917) [Volodymyr Vynnychenko as the editor of the magazine «Promin» (1916-1917)]. Naukovi praci istorichnogo fakul'tetu Zaporiz'kogo nacional'nogo universitetu. 43: 162-167 (in Ukrainian).

2. Bezkrovnij Ju.O. 2015b. Anketa zhurnalu «Ukrainskaja zhizn'» z nacional'nogo pitannja [Questionnaire for the magazine «The Ukrainian Life» on the national issue]. Visnik Harkivs'kogo nacional'nogo universitetu imeni V.N. Karazina. Serija: Istorija, 50: 154-160 (in Ukrainian).

3. Bezkrovnij Ju.O. 2015v. Zhurnal «Ukrainskaja zhizn» i cenzura (1912-1917) [Magazine «The Ukrainian Life» and censorship (1912-1917)]. Etnichna istorija narodiv Yevropy. 46: 86-92 (in Ukrainian).

4. Bezkrovnij Ju.O. 2016. Zhurnalists'ka dijal'nist' Simona Petljuri v Peterburzi ta Moskvi [Journalistic activity of Simon Petliura in St. Petersburg and Moscow]. Naukovi zapiski NaUKMA. Istorichni nauki. 182: 27-35 (in Ukrainian).

5. Idz'o V.S. 2015a. «Ukrainskaja zhizn'» - naukovo-literaturnij i gromads'ko-politichnij zhurnal ukraintsiv Moskvi ta Rosii 1912-1917 rokah [«The Ukrainian Life» as a scientific-literary and sociopolitical journal of Ukrainians in Moscow and Russia in 1912-1917]. L'viv, «Ukraïnoznavec»: 170 p. (in Ukrainian).

6. Idz'o V.S. 2015b. Mihajlo Grushevs'kij na shpal'tah chasopisiv ukraintsiv Rosii «Ukrainskij Vestnik» ta «Ukrainskaja Zhizn'» pershij chverti XX stolittja [The name of Mykhaylo Hrushevsky in the columns of Ukrainian magazines «The Ukrainian Herald» and «The Ukrainian Life» in the first quarter of the twentieth century]. Ivano-Frankivs'k, «Simik»: 24 p. (in Ukrainian).

7. Klopova M.Je. 2015. «Bol'noj vopros». Anketa zhurnala «Ukrainskaja zhizn'» 1912-1917 gg. [The sensitive issue. Questionnaire of the magazine «The Ukrainian Life»]. Slavjanskij al'manah. 3-4: 122-137 (in Russian).

8. Kozar L. 2014. Visvitlennja fol'kloristichno-etnografichnoï dijal'nosti Pavla Chubins'kogo na storinkah zhurnalu «Ukrainskaja zhizn'» [Coverage of folklore and ethnographic activities of Pavel Chubinsky on the pages of the magazine «The Ukrainian Life»]. Slov'jans'kij svit. 13: 260-272 (in Ukrainian).

9. Kolmakov V.B. 2010. Ob odnom nacionalisticheskom narrative nachala XX veka [On a nationalist narrative of the early twentieth century]. Vestnik Voronezhskogo gosudarstvennogo universiteta. Serija: Filosofija. 1 (3): 48-61 (in Russian).

10. Korniievska O.V. 2013. «Ukraynskyi Vestnyk» - Tyzhnevyk (1906) [«Ukrainian vestnik» - a weekly (1906)]. Enciklopedija istorii Ukrainy: u 10 t. Kyiv: Naukova dumka. T. 10: 220 (in Ukrainian). 
11. Mironjuk D.I. 2011. Simon Petljura jak redaktor zhurnalu «Ukrainskaja zhizn'» (1912-1917 rr.) [Simon Petliura as editor of the magazine «The Ukrainian Life» (1912-1917)]. Avtoref. dis. ... kand. nauk iz soc. komunikacij. Kiïv: 20 (in Ukrainian).

12. Mironjuk D.I. 2009. Zhurnal «Ukrainskaja zhizn'» - jak chinnik zahistu ukranskoi movi v umovah nastupu reakcijnih sil na nacional'no-vizvol'nij ruh (1912-1917 rr.) [The magazine «The Ukrainian Life» - as a factor in the protection of the Ukrainian language in the face of the onslaught of reactionary forces on the national liberation movement (1912-1917)]. Naukovi praci Kam'janec'-Podil's'kogo nacional'nogo universitetu imeni Ivana Ogiyenka. Filologichni nauki. 20: 420-425 (in Ukrainian).

13. Mihutina I.V. 2003. Ukrainskij vopros v Rossii (konec XIX - nachalo XX veka) [The Ukrainian issue in Russia (late XIX - early XX century)]. M., «Lovatera»: 287 p. (in Russian).

14. Pashaeva N.M. 1994. Zhurnal «Ukrainskaja zhizn'» [Magazine «The Ukrainian Life»]. Biblioteka i istorija. 3: 81-101 (in Russian).

15. Polumisna O.O. 2007a. Narodnictvo i modernizm v interpretaciï literaturnih kritikiv zhurnalu «Ukrainskaja zhizn'» (1912-1917) [Populism and modernism in the interpretation of literary critics of the magazine «The Ukrainian Life» (1912-1917)]. Visnik Harkivs'kogo nacional'nogo universitetu im. V.N. Karazina. 766. Ser. Filologija. 51: 71-75 (in Ukrainian).

16. Polumisna O.O. 2007b. Kompozicijni osoblivosti literaturno-kritichnih materialiv zhurnalu «Ukrainskaja zhizn'» (1912-1917 pp.) [Compositional features of literary-critical materials of the magazine «The Ukrainian Life»(1912-1917 pp.)]. Visnik Harkivs'kogo nacional'nogo universitetu im. V.N. Karazina. 787. Ser. Filologija. 52: 297-301 (in Ukrainian).

17. Polumisna O.O. 2009a. Organizacijna dijal'nist' redaktors'kogo skladu zhurnalu «Ukrainskaja zhizn'» (1912-1917 pp.) [Organizational activity of the editorial staff of the magazine «The Ukrainian Life» (1912-1917)]. Visnik Harkivs'kogo nacional'nogo universitetu im. V.N. Karazina. 846. Ser. Filologija. 56: 191-196 (in Ukrainian).

18. Polumisna O.O. 2009b. Zhurnal «Ukrainskaja zhizn'» i literaturnij proces pochatku XX stolittja [Magazine «The Ukrainian Life» and the literary process of the early twentieth century]. Avtoref. dis. ... kand. filol. nauk. Harkiv: 19 (in Ukrainian).

19. Polumisna O.O. 2010. Dijal'nist' zhurnalu «Ukrainskaja zhizn'» (1912-1917) v ocinci ukrainskykh i rosijs'kih periodichnih vidan' pochatku XX stolittja [Edition of the magazine «The Ukrainian Life» (1912-1917) in the assessment of Ukrainian and Russian periodicals of the early XX century)]. Visnik Harkivs'kogo nacional'nogo universitetu im. V.N. Karazina. № 910. Ser. Filologija. 60, chast. II: 412-415 (in Ukrainian).

20. Polumisna O.O. 2014. Simon Petljura: literaturnij kritik, publicist, redactor [Simon Petliura: literary critic, publicist, editor]. Visnik L'vivs'kogo universitetu. Serija: Zhurnalistika. 39(1): 289-296 (in Ukrainian).

21. Sergijchuk G. 2016. Spivpracja M. Grushevs'kogo z ukraintsiamy Moskvi na pochatku XX stolittja [Cooperation of M. Hrushevsky with the Ukrainians of Moscow in the early XX century]. Shid. 4 (144): 73-78 (in Ukrainian).

\section{ИНФОРМАЦИЯ ОБ АВТОРАХ}

Трофимов Роман Викторович, аспирант кафедры российской истории и документоведения Белгородского государственного национального исследовательского университета, г. Белгород, Россия

Мошкин Александр Николаевич, доктор исторических наук, профессор, ведущий научный сотрудник НИЛ исторической антропологии Белгородского государственного национального исследовательского университета, г. Белгород, Россия

\section{INFORMATION ABOUT THE AUTHORS}

Roman V. Trofimov, post-graduate student of the Department of Russian History and Documentation of the Belgorod National Research University, Belgorod, Russia

Aleksandr N. Moshkin, Doctor of Historical Sciences, Professor, Leading Researcher of the Research Laboratory of Historical Anthropology, Belgorod National Research University, Belgorod, Russia 